\begin{tabular}{|l|l|}
\hline HISTÓRIAS DA INTOLERÃNCIA & 10 \\
\hline
\end{tabular}

ILANA WAINGORT NOVINSKY

Em busca da verdade

em tempos sombrios

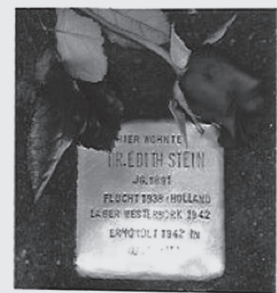

Edith Stein

IFAPESP MUMANITAS

\title{
Filósofa e santa
}

Mário Miranda Filho

Em Busca da Verdade em Tempos Sombrios - Edith Stein,

de Ilana Waingort Novinsky, São Paulo, Humanitas, 2014, 336 pp. 
"Jamais houve até o presente subserviência pela consciência comparável àquela que o século XX conheceu."

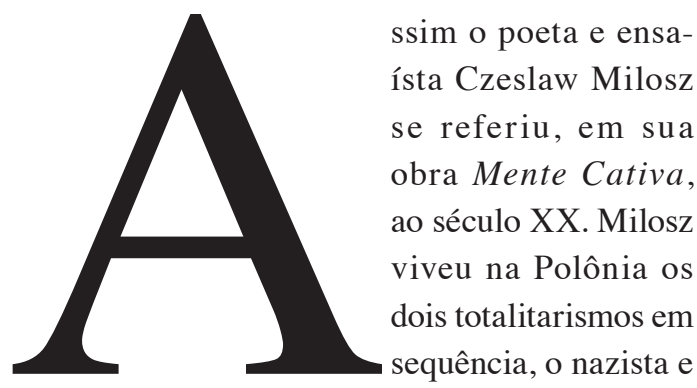

o soviético, e conheceu de perto o fenômeno da prisão mental, ou seja, da ideologia que tanto a Alemanha quanto a extinta URSS impuseram aos países que invadiram. Sua obra tornou-se um alerta sobre o quanto é possível, e mesmo relativamente fácil, fazer com que o domínio das botas seja completado pelo das mentes e do quanto pode ser trágico para qualquer país a função subserviente dos intelectuais na política.

Prisão mental: a expressão nos remete aos filósofos que fundaram a filosofia e que estavam pela primeira vez se defrontando com a questão do aprisionamento de que todos podemos ser vítimas, sobretudo quando os ferros físicos que prendem nossas pernas são substituídos pelos ferros psíquicos com que as ideologias tentam prender nossas mentes, impedindo-nos de pensar. Afinal, essa forma de libertação pelo conhecimento é a imagem arquetípica do trabalho realizado pela filosofia, tal como Platão a apresenta na alegoria da caverna. Vemos ali como, num mundo privado de filosofia, nascemos e crescemos aprisionados em obscuras cavernas onde só podemos ver imagens e simulacros que tomamos como a realidade.

O filósofo nos mostra então em que consiste o trabalho de educação filosófica para uma mente livre, e ele começa não com um passo à frente, mas, por um movimento de reviravolta, com um voltar-se sobre si mesmo e, através de uma conversão, dando as costas às imagens e simulacros e encaminhando-se para o exterior da caverna, para a realidade e a verdade.

Lembrei-me de Milosz e de Platão, desses dois notáveis teóricos da prisão mental, ao ler cada pá- gina da saga de Edith Stein, tal como ela nos é apresentada neste livro magistral de Ilana Waingort Novinsky, pois ela nos mostra os extraordinários esforços empreendidos por Stein em sua busca da verdade. Busca que se cumpre sob a determinação da conversão, inicialmente uma conversão à filosofia, em seu encontro com a fenomenologia de E. Husserl e, posteriormente, ao cristianismo. Dupla conversão, portanto, eis o feito paradoxal de Edith e o extraordinário desafio a que teve que responder Ilana em sua pesquisa. Digo bem, extraordinário, pois Edith não se contentou, ao descobrir a filosofia, em se emancipar da tradição judaica em que fora criada, mas, num segundo passo, ousou negar sua primeira negação sob o efeito agora de seu encontro místico com a Cruz, como ela dizia.

Em sua época eram comuns, como mostra Ilana, os casos de judeus que, por motivos vários, se convertiam ao cristianismo (como ocorreu com amigos seus). Mas o caso de Edith é peculiar, pois se trata de uma doutora em filosofia (uma das dez primeiras mulheres da Alemanha a obter tal título) cuja tese elaborou questões trazidas por uma corrente filosófica de vanguarda nas primeiras décadas do século XX. Pois essa vanguardista, não contente em romper com os laços da tradição em que fora criada, rompeu também com os parâmetros positivistas da vida acadêmica ao entrar para o convento das carmelitas, recusando assim, na prática, o dogma da incompatibilidade entre a ciência e a religião. Seu gesto parece, à primeira vista, portanto, um passo atrás, e houve quem o interpretasse como uma traição e a própria autora chega a julgar incompreensível que Edith o tivesse feito em 1933, momento crítico para os judeus alemães.

A fenomenologia a encantou desde cedo por propor uma via alternativa aos excessos formais do racionalismo neokantiano vigente à época. Sua proposta de "ir às coisas mesmas", de buscar o concreto, de lutar contra todos os tipos de pressupostos que até então orientavam o pensamento abria um horizonte repleto de possibilidades para a jovem que antecipou sua vida como uma missão e que se acreditava destinada "a algo grande".

MÁRIO MIRANDA FILHO é professor do Departamento de Filosofia da FFLCH-USP. 
Certamente, essa nova disposição intelectual mostrou-se sempre frutífera e enriquecedora para Edith, em seus trabalhos de filosofia, de pedagogia, em sua atuação feminista e na psicologia. Como sublinha Ilana, tudo isso se dá no momento histórico em que Freud proclama o caráter ilusório da religião, dogma "compartilhado por muitos ainda hoje" (p. 236).

Já convertida ao cristianismo, Edith ensina por nove anos no Colégio Dominicano de Santa Madalena, em Speyer, desenvolvendo novas perspectivas pedagógicas (que incluem orientação sexual para as alunas). Mas, já sob o pathos da nova conversão da cruz, não se limita a aplicar o método fenomenológico ao que seus olhos e seus sentidos veem, ao plano do mundano. Vai além, submetendo também os fenômenos religiosos ao novo método. O que leva Ilana a perguntar:

"Até que ponto a fenomenologia contribuiu para essa escolha? A procura da essência com certeza fez parte do seu caminho, permitiu seu olhar para o ontológico do ser humano e levou-a até a mística, não como uma alternativa à pesquisa racional, mas como um caminho alternativo em direção à Verdade" (p. 278).

De fato, diz a autora, sem nunca ter abandonado a fenomenologia, "seu tema de pesquisa, aquele em que mostrou sua originalidade, é o ser humano, contemplado em sua vida psíquica, nas suas manifestações espirituais, nas suas diferenças sexuais, na sua vida comunitária" (p. 167). E a vida psíquica, ela não a podia conceber senão em sua integridade, e não de modo compartimentado, como seccionada dos fenômenos religiosos.

Diz Ilana:

“Toda a questão para Edith é procurar, a partir da experiência de si, do método fenomenológico, poder vislumbrar o Divino. O objetivo é, através da introspecção de si mesmo, do acolhimento do fenômeno daquilo que se é, poder ter uma visão da questão divina, da questão do Sentido do ser... Mostra que o homem precisa de sustentação para ter o Ser, o que revela a sua relação com o Divino" (pp. 263-4).

Pois, realmente, se, por um lado, a descoberta da fenomenologia husserliana representou uma li- bertação, por outro, "o sol de Cristo, que começou a se levantar em seu coração" e diante do qual sua "incredulidade cedeu", representou para a já madura filósofa um "renascimento" capaz até mesmo de aliviar sua depressão (p. 157).

Vemos como Edith, num gesto de lealdade para consigo mesma, e para desgosto de familiares e colegas, judeus ou não, leva a fidelidade ao seu próprio ser, ao seu próprio sentir às últimas consequências, não se detendo diante das demarcações convencionais que então, e hoje ainda, delimitam prudentemente as áreas das ciências e das religiões. Como poderia fazê-lo alguém que soube encarar a teratológica e covarde máquina de destruição de vidas nazista com a convicção e altivez dos mártires, dedicando-se a consolar as crianças à beira dos crematórios de Auschwitz, como nos conta a autora, citando o seguinte testemunho de um prisioneiro sobrevivente?

“[...] irmã Benedita [Teresa Benedita da Cruz foi o nome que adotou] se destacava por sua calma e postura. O desespero nas barracas e a agitação causada pela chegada dos novos prisioneiros eram indescritíveis. Irmã Benedita era como um anjo, andando entre as mulheres, ajudando e acalmando-as. Muitas mães estavam como que enlouquecidas, não cuidavam mais de seus filhos, apenas sentadas melancolicamente, em desespero e depressão. Irmã Benedita cuidou das crianças pequenas, lavou-as e penteou-as, alimentando-as e cuidando de suas necessidades. Durante toda sua estada lá, lavou e limpou as pessoas, fazendo um ato de caridade atrás do outro, até que todos notaram sua bondade" (p. 190).

Como se vê, a segunda conversão de Edith em nada afetou sua disposição filantrópica e caridosa. Ao contrário, como ocorreu com tantos outros religiosos, a fé reforçou sua determinação de se opor à barbárie (como não lembrar aqui, por exemplo, dos bravos jovens cristãos do grupo Rosa Branca da Universidade de Munique, Hans Scholl, sua irmã Sophie e Christoph Probst - entre 22 e 24 anos -, presos, "julgados" e guilhotinados - tudo em quatro dias! - em fevereiro de 1943, por distribuírem panfletos contra o regime nazista?).

Foi como se a prisioneira Edith, com seu gesto de amor e coragem, quisesse reafirmar 
uma última vez a fecundidade da síntese entre o saber filosófico e a fé no mundo dos homens, para além do plano teórico.

Portanto, diante da grandeza com que soube transformar sua vida, em que conseguiu harmonizar os dotes intelectuais e a caridade, toda a questão sobre a viabilidade da união entre razão e fé se torna, em seu caso, nada mais do que mero exercício acadêmico. Claro, isso não poderia impedir que os estudiosos de sua vida e obra manifestassem seu desconcerto diante de sua singular humanidade. E o leitor desse livro verá que sua autora não foi a primeira, nem terá sido a última, a sentir em profundidade o choque do contato com essa filósofa e santa.

Ilana, de fato, não se propôs a fazer mais uma biografia de Edith. Escorada na psicanálise, mas numa vertente analítica que já incorpora os legados da própria Edith, nutridos, expandidos e metabolizados por outras contribuições, como as de Heidegger, Levinas, Winnicott e de Gilberto Safra inter alia, nossa autora leva adiante o que designa de modo muito original como uma busca da "verdade emocional". Trata-se de uma expansão da atividade clínica para além do consultório. Assim, nossa autora, fiel ao seu métier, não se furta a proceder àquilo que um neófito no assunto como eu designaria como uma espécie de psicanálise ontológica de Edith (ou o que os heideggerianos designam geralmente de "daseinsanálise") ${ }^{1}$. Mas ela não se lança nessa arrojada e arriscada empreitada desprovida de recursos. Ao contrário, o leitor verá que ela se põe a campo bem equipada, munida de conceitos como "acolhimento", "idioma pessoal", "fragmentação ética", "falha ética", "mitopoiesis", "rosto", "sobornost" e tantos outros mais, hauridos nos autores acima mencionados, na tentativa de dar conta do caráter enigmático da vida e obra de Edith Stein. Por fim, ultrapassando a advertência de um de seus mestres, Levinas, que dizia "jamais posso nomear a totalidade que é o outro", chega a aventurar a hipótese de algo próximo a um diagnóstico. De fato, referindo-se à opção de Edith pelo convento, pergunta se essa "escolha não seria uma falha ética, para com todos os seus e para com esta mesma humanidade?" (p. 278). E responde duramente à sua própria questão: "[...] ao retirar-se do mundo, Edith trai os que pretende salvar" (p. 278).

Traição que, no caso, é entendida como sua opção radical por Jerusalém, mais precisamente, por sua entrada para o convento.

Assim, ao proferir esse julgamento, Ilana, por sua vez, permanece fiel à tradição de Atenas, à tradição daqueles que pensavam, como Sócrates, que uma vida de obediência incondicional a um Deus inescrutável, tal como a Bíblia exige de seus fiéis, uma vida sem zétesis, sem exame, não tem sentido.

Já ao final de sua obra, Ilana nos fala da tensão a que se viu submetida desde o início de seu trabalho sobre a figura enigmática de Edith Stein e de como essa tensão ainda se mantém para além da conclusão da obra. Essa sua confissão, pouco habitual nos trabalhos acadêmicos, sempre preocupados com a isenção, de algum modo atenua a dureza de seu julgamento referido acima. E, numa demonstração de que esse seu estado de alma não provém apenas da singularidade de sua subjetividade, ela nos remete às belas reflexões de um contemporâneo de Stein, o filósofo Leo Strauss, que, em sua conferência sobre Jerusalém e Atenas, isto é, sobre a religião revelada e a filosofia, pôde justamente mostrar como essas duas robustas e indestrutíveis raízes constituem a insolúvel tensão que define o Ocidente.

Nesse sentido é que podemos compreendê-la melhor quando diz que Edith é "alguém com quem se tem muito que aprender" (p. 287). Ilana terá aprendido com essa mestra, que soube estabelecer um diálogo fértil entre a religião e a filosofia, a se manter na tensão fecunda desse diálogo. E nós, leitores, de nossa parte, podemos também, a partir de agora, meditando sobre esse belo livro, aprender com Edith e com Ilana que nossa humanidade se desenvolve diante de múltiplos horizontes, e que o niilismo de nossa época não tem necessariamente o caráter inexorável que lhe atribuem Nietzsche e seus discípulos.

1 É claro que a autora do presente livro não se identifica rigorosamente com os conteúdos da análise heideggeriana. 